\title{
Development of Automated Assessment Tool to Measure Student Creativity in Computer Programming
}

\author{
Ricky E. Putra ${ }^{1,{ }^{*}}{\text { Ekohariadi Ekohariadi }{ }^{1},{ }^{1} \text { K. D. Nuryana }}^{1,}$ Yeni Anistyasari $^{1}$ \\ ${ }^{1}$ Informatics Department, Universitas Negeri Surabaya, Indonesia \\ *Corresponding author.Email: rickyeka@unesa.ac.id
}

\begin{abstract}
Computer programming is one of the fa vorite learning topics a mong students in the 21 st century. However, the students creative thinking skills are often less able to compensate for this computer programming learning. One of the learning activities applied to hone students' creativity in computer programming is digital storytelling. Through the results of these activities, lecturers can measure the level of students' creativity. The mea surement of student creativity uses four factors (fluency, flexibility, origina lity, and elaboration). This study proposes an a utomated assessment tool system that can objectively measure these four factors without requiring a long time. This software development process uses one of the software developments models, namely the waterfall model. The ease of use of this m odel makes developers use it a lot in making various software. The automated assessment tool can be a practical solution in supporting students' creative thinking skills in computer programming. The values of the four factors generated from the a pplication will be calculated for correlation. The correlations of fluency, flexibility, originality, and elaboration test items obtained were $0.69,0.75,0.73$, and 0.79 , while the reliability of the creativity test alpha was 0.73 .
\end{abstract}

Keywords: Automated assessment tool, Creative thinking, Computer programming.

\section{INTRODUCTION}

Creative thinking skills have become a priority in the 21 st century, marked by the explosion of science and technology innovation in all fields [1]. In this era, computing is the main activity of daily life. It makes Informatics, which focuses on programming, expertise with many enthusiasts. In recent years, Vocational High School has opened a Computer and Informatics Engineering expertise program to seize this opportunity.

Students' primary challenge when programming is finding creative solutions corresponding to specific requirements [2]. Some students are not proficient in programming because they lack creative thinking skills [3]. It resulted in the students' motivation towards programming being low. Creative thinking is characterized as flexible, imaginative, innovative thinking that employs all one's skills and abilities [4]. Creative thinking will create new and intelligent solutions in answering computational problems and increasing the effectiveness of solutions in programming [5]. Therefore, creativity is needed to create a reliable program and can answer the existing problems. Digital storytelling is a learning technique to increase creativity in computer programming.

The most often used test to measure creativity is the Torrance Tests of Creative Thinking (TTCT) [6] and is designed from Guilford's idea of divergent thinking. There are four levels measured by this test, namely fluency, flexibility, originality, and elaboration. Fluency is the ability to generate many ideas or problem answers quickly. Flexibility means the ability to suggest several approaches to a specific problem simultaneously. Origina lity is the ability to come up with new and original concepts. Elaboration is the ability to categorize and organize pictures in mind and apply them to action. The figural test is one form of TTCT (TTCT-F) with three activities: image construction, drawing completion, and line repetition [7].

It is not easy to measure creativity in education because it requires assessors who are trained in processing responses. The results of the creativity assessment obtained also vary because it depends on the interpretation of every assessor. Therefore, the interassessor reliability is low [8]. This causes the 
measurement results to be inconsistent, so an assessment tool is needed that is objective and not influenced by subjectivity.

The development of this assessment tool application uses the waterfall software development model that has been done previously $[9,10]$. This development model consists of five stages: requirements analysis, design, implementation, verification, and maintenance. This model has advantages in a structured work process to minimize errors in application development. This development model also includes a simple development model so that developers can easily apply this development model in various application creations.

The application to be built also utilizes digital image processing techniques because the input obtained by this system is video. Digital image processing techniques are obtained from several related studies that have been done previously $[11,12,13]$

This paper proposes a new method by utilizing computer technology to measure students' creativity in computer programming using an automated assessment tool. The computerized assessment tool to measure creativity based on the TTCT-F developed in this study is something new and has not been done by other researchers.

\section{LITERATURE REVIEW}

\subsection{Creativity in Computer Programming}

Educational institutions must prepare students to face challenges creatively that result in unique solutions. Creative thinking is associated with efforts to produce changes or ideas, solutions, concepts, and theories characterized by uniqueness and originality [14], [15]. Creative thinking results from the synthesis and formulation of ideas. The results of creative thinking are new ideas that others have never produced before [16]. One form of creativity assessment test is the Torrance Tests of Creative Thinking (TTCT) which consists of fluency, flexibility, originality, and elaboration [6]. The results of TTCT respondents' answers were corrected manually by comparing the results of each respondent with other respondents in a sample [17, 18, 19, 20, 21]. Manual correction is expensive, unavoidable assessor subjectivity, and less reliable [22].

The use of technology to measure student creativity was proposed by [21, 22]. Wang [22] proposed an automated assessment grading to assess students' creativity. The empirical evaluation results show that automatic assessment is reliable for identifying students' creativity. However, Wang et al.'s research focuses on automated a ssessment grading for TTCT verbal forms in the form of Chinese text. Pásztor [23] developed a technology-based assessment using divergent thinking theory to measure students' creativity. The technology- based evaluation was designed for figural and web-ba sed TTCT. The weakness of this method is that the assessment is not fully automated. The answers must be categorized manually.

The recommended form of creativity assessment for adolescent students is digital storytelling [24, 25, 26]. The digital storytelling concept emerged in the 1990s and was developed by the Center for Digital Storytelling in America. The digital storytelling concept has been recognized as a constructivist learning strategy supporting project-based, technology-integrated, student-centered learning experiences. The concept of digital storytelling is defined as storytelling or personal narrative related to the use of digital technology to construct meaning [24]. The term digital storytelling is also defined as the art of combining narration with digital media such as images, sound, and video to create short stories [27]. As such, digital storytelling is distinguished from traditional storytelling by its technology-defining features and applications in digital storytelling. Digita 1 storytelling artifacts are made in short films, lasting two to three minutes [25]. Several studies have shown that digital storytelling can increase students' motivation, learning autonomy, and involvement [26]. Other studies also show that digital storytelling can contribute to higher-order thinking, such as critical thinking and creative thinking [25].

With the traditionalapproach, programming concepts are handled separately, not linked to other fields in computer programming learning. This situation increases students' learning difficulties and lecturers' teaching difficulties. Furthermore, digital storytelling is considered suitable for solving this challenge [28]. The process of making digital storytelling consists of four primary stages [29], namely (a) setting the stage, (b) story design, (c) digital story development, and (d) digital story assessment. Digital storytelling has also been widely applied as a learning medium to support computer programming [30]. Digital storytelling allows programmers to become creative storytellers using various technologies, including Scratch. Scratch is a visual programming environment that will enable users to create personally meaningful projects such as games, simulations, stories, and greeting card designs [31]. Assessment of student creativity through digital storytelling is based on four TTCT-F rating scales, namely fluency, flexibility, originality, and elaboration [6].

\subsection{Waterfall Model}

This research utilizes the Waterfall software development model. Winston Royce developed this fivestage model (Figure 1). This classical development model with a linear development system [32] has requirements analysis, design, implementation, verification, and maintenance stages. 


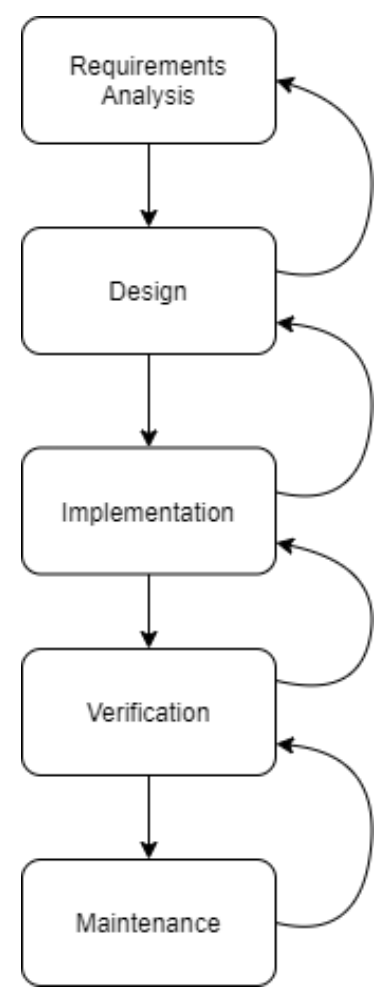

Figure 1 Waterfall model.

\subsection{Image Processing}

The input in this application is in the form of video. The video itself is a collection of several images in a particular timeline. Several photos displayed in sequence at a specific time make the image display move to become a video. Therefore, video processing can also be done using image processing techniques.

Some of the activities that can be carried out on the input video include measuring video time duration, determining keyframes, measuring similarity to other videos, and measuring image morphology or texture using Gray Level Co-occurrence Matrix (GLCM).

\section{METHODS}

Student creativity can be measured based on four components: fluency, flexibility, originality, and elaboration of the created digital storytelling. Each of these components has a different measurement process. The video processing process to obtain student creativity scores is explained as follows.

\subsection{Dataset}

The research conducted at the Department of Informatics Engineering, Faculty of Engineering, Universitas Negeri Surabaya, involved 71 respondents. The learning carried out in this research is applied to introductory programming courses with a visual programming language. Each student is free to decide what they will do while the project assignment is digital storytelling.

\subsection{Fluency Measurement}

Fluency is defined as the ability to generate several ideas or problem solutions in a short time. In digital storytelling, fluency is analogous to the duration of the successfully created video. A long video duration can indicate a person's fluency in digital storytelling. The process starts by creating an object from the Video Reader that reads the files that contain videos.

The thing is formed from the Video Readerfunction, queries information about the video using object properties, and reads the video using object functions. The object contains information about the video file and allows reading data from the video. Next, the video duration is calculated using the Duration function. Video duration is calculated in seconds. Duration is a scalar quantity, and data type is double.

After obtaining the duration of the digital storytelling video, the value is converted to a fluency score with the following conditions: (1) if the video duration is less than 60 , then the fluency score is 0 ; (2) if the video duration is less from 60 to 120 then the fluency score is 1 ; (3) if the video duration is more than 120 then the fluency score is maximum or 2 . If $\mu$ is the fluency score and $d$ is the video duration in seconds, then the fluency rating is written formally in equation 1 .

$\mu=\left\{\begin{array}{c}0, \text { ifd }<60 \\ 1, \text { if } 60 \leq d \leq 120 \\ 2, \text { if } d>120\end{array}\right.$

\subsection{Flexibility Measurement}

Flexibility is the ability to propose various solutions to specific problems simultaneously. Flexibility can be interpreted as the degree of difference in answers, namely the number of categories included. This definition is assumed to be the number of characters created in digital storytelling.

If students can create more than 20 types of characters, they get a maximum score of 2. Conversely, a minimum score is given if students generate less than ten characters. A score of 1 is obtained if $10-20$ types of characters are created. To get a flexibility score, the number of characters between digital storytelling videos produced by a student is compared. The procedure used is shown in Figure 2.

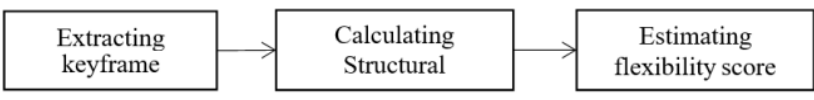

Figure 2 Flexibility score measurement process. 


\subsection{Originality Measurement}

Origina lity is the ability to generate new and origina 1 ideas. Like flexibility, originality scores were obtained by comparing different characters produced by students in digital storytelling. The difference is the flexibility of reaching between characters in a video and originality comparing between characters in all videos stored in the system database.

\subsection{Elaboration Measurement}

Elaboration is the ability to systematize and organize the details of an idea in the head and then execute it. In other words, elaboration is the level of detail of a response. One way to measure the detail of an image is to measure the morphology or texture using the Gray Level Co-occurrence Matrix (GLCM). Gray Level Cooccurrence Matrix (GLCM) is a matrix that represents the neighboring relationship between pixels (co-occurrence) in various orientation directions and spatialdistances.

\section{RESULTS AND DISCUSSION}

This chapter is divided into three sub-chapters: the display of the application that was built, the results of descriptive statistics on creative thinking, and the reliability of the creative thinking test.

\subsection{The Display of Automated Assessment Tool}

Application users can choose the "Extract Keyframes" menu and upload videos from digital storytelling by pressing the "Upload Video" button. The inserted video file must have an MP4 extension. When the user has uploaded the file, the a pplication will process the file. After some time, the program will display the results of the Fluency, Flexibility, Originality, and Elaboration calculations, as shown in Figure 3.

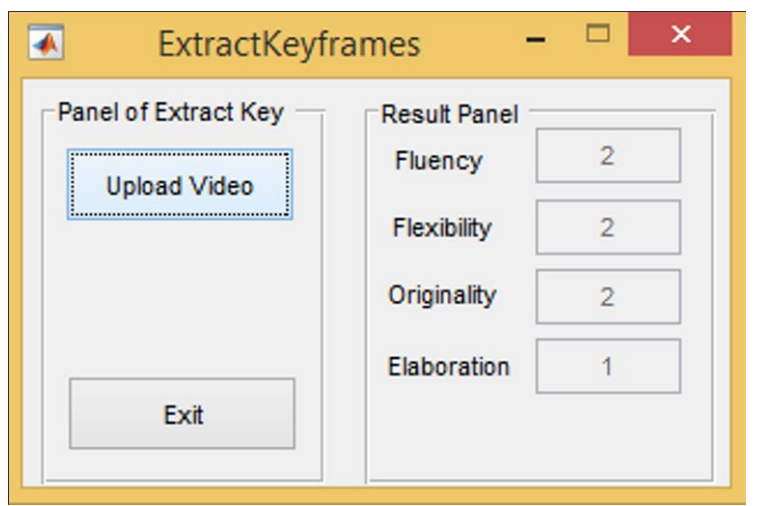

Figure 3 Flexibility score measurement process.

\subsection{Descriptive Statistics on Creative Thinking}

The summary of creative thinking scores consisting of fluency, flexibility, originality, and elaboration is shown in Figure 4. The score ranges from 0 to 2 . The respondents are 71 students. Figure 5, Figure 6, Figure 7, and Figure 8 show the histogram of each creative thinking score.

\begin{tabular}{r|rrrrr} 
Variable & Obs & Mean & Std. Dev. & Min & Max \\
\hline fluency & 71 & .9859155 & .7069645 & 0 & 2 \\
flexibility & 71 & .9577465 & .7826077 & 0 & 2 \\
originality & 71 & 1.028169 & .736242 & 0 & 2 \\
elaboration & 71 & 1 & .8106435 & 0 & 2
\end{tabular}

Figure 4 Creative thinking score summary.

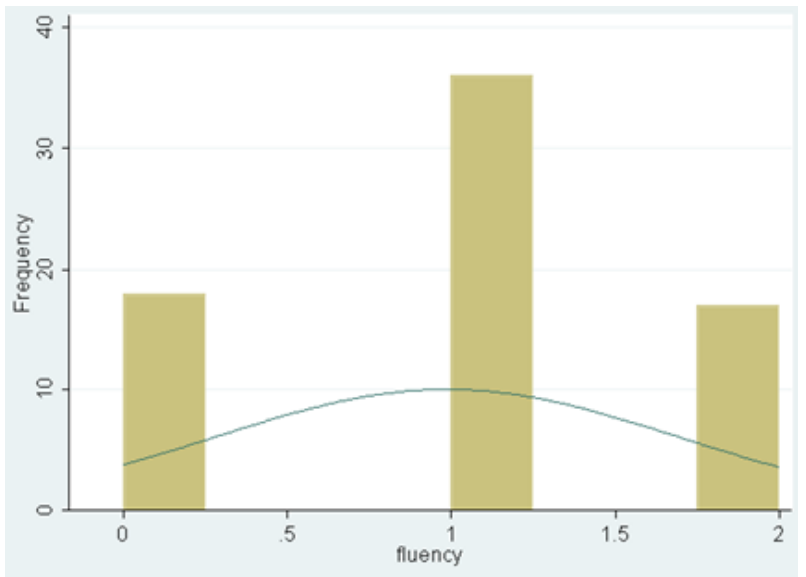

Figure 5 Fluency score histogram.

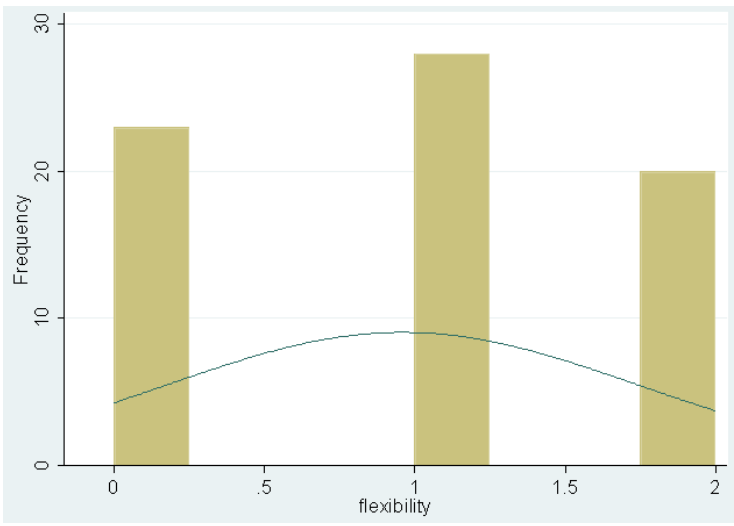

Figure 6 Flexibility score histogram.

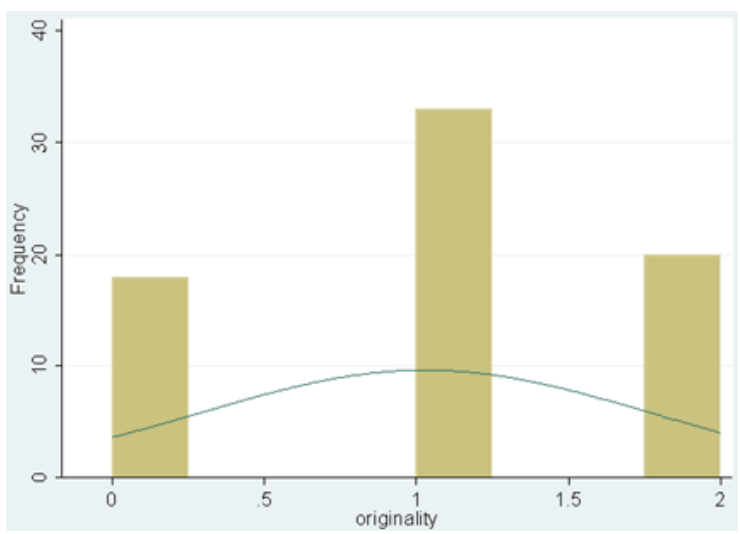

Figure 7 Originality score histogram. 


\subsection{Reliability of The Creative Thinking Test}

The reliability of a test refers to the consistency of individual ratings obtained from the test results being taken more than once. In other words, a test is reliable if it consistently produces the same rating or is close to the same on repeated implementations. The reliability of the creative thinking score is calculated using the alpha coefficient formula (equation 2) with $\sigma_{i t e m}^{2}$ is the variance of each item and $\sigma_{x}^{2}$ is the variance of the test scores.

$\alpha=\frac{k}{k-1}\left(\frac{\sum \sigma_{\text {item }}^{2}}{\sigma_{x}^{2}}\right)$

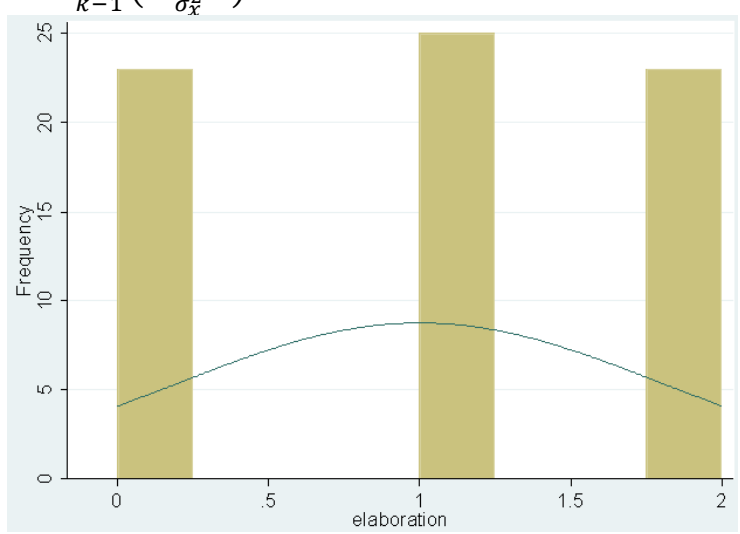

Figure 8 Elaboration score histogram.

The results of the reliability analysis are shown in Figure 9. It also shows the correlation of fluency, flexibility, originality, and elaboration test items.

\begin{tabular}{l|cccccc} 
Item & Obs & Sign & $\begin{array}{c}\text { item-test } \\
\text { correlation }\end{array}$ & $\begin{array}{c}\text { item-rest } \\
\text { correlation }\end{array}$ & $\begin{array}{c}\text { average } \\
\text { interitem } \\
\text { covariance }\end{array}$ & alpl \\
\hline fluency & 71 & + & 0.6898 & 0.4611 & .2623072 & 0.69 \\
flexibility & 71 & + & 0.7521 & 0.5237 & .2239437 & $0.66:$ \\
originality & 71 & + & 0.7319 & 0.5113 & .237894 & $0.66 !$ \\
elaboration & 71 & + & 0.7893 & 0.5735 & .2003353 & 0.63 \\
\hline Test scale & \multicolumn{1}{|c}{} & & & .2311201 & 0.72 \\
\hline
\end{tabular}

Figure 9 Creative thinking score reliability coefficient.

\section{CONCLUSION}

Automated assessment tools to mea sure creativity are needed in the field of education. Therefore, this study developed an automated assessment tool by following the steps in a simple and linearly structured software development model, namely the waterfall model. There are five stages referred to in the model, namely requirements analysis, design, implementation, verification, and maintenance.

The application results will be recapitulated, the descriptive statistical values calculated, and the histogram displayed. Next, the activity continues calculating the correlation of each test item. The correlations of fluency, flexibility, originality, and elaboration test items are $0.69,0.75,0.73$, and 0.79 . The reliability of the creativity test alpha is 0.73 .

Future work is needed to investigate the validity of creative thinking and computational thinking constructs, whether they are different or the same. In computer programming, these two constructs are fundamental.

\section{AUTHORS' CONTRIBUTIONS}

All authors conceived and designed this study. All authors contributed to the process of revising the manuscript, and at the end all authors have approved the final version of this manuscript.

\section{ACKNOWLEDGMENTS}

This work is supported by funding from the Faculty of Engineering, Universitas Negeri Surabaya, Indonesia.

\section{REFERENCES}

[1] Ekohariadi, Y. Anistyasari, R. E. Putra, "Rasch and Classical Test Theory Validation of Automated Assessment Tool for Measuring Students' Creativity in Computer Programming", in International Joint Conference on Arts and Humanities (IJCAH 2020), pp. 1155-1160, 2020.

[2] P. Schaumont, I. Verbauwhede, "The Exponential Impact of Creativity in Computer Engineering Education,"pp. 17-20, 2013.

[3] L. D. Miller, L. Soh, V. Chiriacescu, E. Ingraham, D. F. Shell, and M. P. Hazley, "Improving Learning of Computational Thinking Using Creative Thinking Exercises in CS-1 Computer Science Courses," in IEEE Frontiers in Education Conference (FIE), pp. $1-7,2013$.

[4] R. E. Franken, Human motivation. Australia; Belmont, CA: Thomson/Wadsworth, 2007.

[5] M. S. Peteranetz, A. E. Flanigan, D. F. Shell, and L. K. Soh, "Computational Creativity Exercises: An Avenue for Promoting Learning in Computer Science," IEEE Trans. Educ., vol. 60, no. 4, pp. 305$313,2017$.

[6] J. P. Guilford, Fundamental Statistics in Psychology and Education. 1978.

[7] K. H. Kim, "The Torrance Tests of Creative Thinking - Figural or Verbal: Which One Should We Use?," Creat. Theor. - Res. - Appl., vol. 4, no. 2, pp. 302-321, 2018.

[8] Cropley, D. H., \& Kaufman, J.C. (2012). Measuring Functional Creativity: Non-Expert Raters and the Creative Solution Diagnosis Scale. The Journal of Creative Behavior, 46(2), 119-137. doi:10.1002/jocb.9

[9] R. E. Putra, I. M. Suartana, "Development of Smart and Interactive Laboratory Management System (SILMS)," in 4th International Conference on 
Vocational Education and Electrical Engineering: Strengthening Engagement with Communities Through Artificial Intelligence Application in Education, Electrical Engineering and Information Technology (ICVEE 2021), 2021.

[10]R. E. Putra, A. I. Nurhidayat, A. Y. Wicaksono, "Implementation of Neural Network to Determine the New College Students," IOP Conference Series: Materials Science and Engineering, 2018.

[11] N. Rochmawati, I. G. P. A. Buditjahjanto, R. E. Putra, A. Y. Wicaksono, "A Responsive Web-Based QR Code for Inventory in the Laboratory of Informatics Unesa," IOP Conference Series: Materials Science and Engineering, 2018.

[12]R. E. Putra, H. Tjandrasa, N. Suciati, "Severity Classification of Non-Proliferative Diabetic Retinopathy using Convolutional Support Vector Machine," International Journal of Intelligent Engineering and Systems, vol. 13(4), pp. 156-170, 2020.

[13]H. Tjandrasa, R. E. Putra, A. Y. Wijaya, I. Arieshanti, "Classification of Non-Proliferative Diabetic Retinopathy Based on Hard Exudates using Soft Margin SVM," in 2013 IEEE International Conference on Control System, Computing and Engineering, ICCSCE 2013.

[14][K. Soh, "Creativity fostering teacher behaviour around the world: Annotations of studies using the CFTIndex," Cogent Educ., vol. 2, no. 1, p. 1034494, 2015.

[15]H. Chun Wang, "Fostering learner creativity in the English L2 classroom: Application of the creative problem-solving model," Think. Ski. Creat., vol. 31, pp. 58-69, Mar. 2019.

[16]F. Jhon, Creative Thinking And Problem Solving. New York: CRC Press, 2017.

[17] G. Krumm, V. Arán Filipppetti, V. Lemos, J. Koval, and C. Balabanian, "Construct validity and factorial invariance across sex of the Torrance Test of Creative Thinking - Figural Form A in Spanishspeaking children," Think. Ski. Creat., vol. 22, pp. 180-189, Dec. 2016.

[18] J. Hahm, K. K. Kim, and S.-H. Park, "Cortical correlates of creative thinking a ssessed by the figural Torrance Test of Creative Thinking," Neuroreport, vol. 30, no. 18, pp. 1289-1293, Dec. 2019.

[19] S. Said-Metwaly, B. Fernández-Castilla, E. Kyndt, and W. Van den Noortgate, "The Factor Structure of the Figural Torrance Tests of Creative Thinking: A Meta-Confirmatory Factor Analysis," Creat. Res. J., vol. 30, no. 4, pp. 352-360, Oct. 2018.

[20]K. H. Kim, "The Torrance Tests of Creative Thinking - Figural or Verbal: Which One Should We Use?," Creat. Theor. - Res. - Appl., vol. 4, no. 12, pp. 303-320, 2017.

[21]S. Humble, P. Dixon, and E. Mpofu, "Factor structure of the Torrance Tests of Creative Thinking Figural Form A in Kiswahili speaking children:
Multidimensionality and influences on creative behavior," Think. Ski. Creat., vol. 27, pp. 33-44, Mar. 2018.

[22] H. C. Wang, C. Y. Chang, and T. Y. Li, "Assessing creative problem-solving with automated text grading," Comput. Educ., vol. 51, no. 4, pp. 14501466, 2008.

[23] A. Pásztor, G. Molnár, and B. Csapó, "Technologybased assessment of creativity in educational context: The case of divergent thinking and its relation to mathematical achievement," Think. Ski. Creat., vol. 18, pp. 32-42, 2015.

[24] P. R. Lim and N. M. Noor, "Digital Storytelling as a Creative Teaching Method in Promoting Secondary School Students' Writing Skills," Int. J. Interact. Mob. Technol., vol. 13, no. 7, pp. 117-128, 2019.

[25] Y. T. C. Yang, Y. C. Chen, and H. T. Hung, "Digita 1 storytelling as an interdisciplinary project to improve students' English speaking and creative thinking," Comput. Assist. Lang. Learn., 2020.

[26] Y. T. C. Yang and W. C. I. Wu, "Digital storytelling for enhancing student academic achievement, critical thinking.; Learning motivation: A year-long experimental study," Comput. Educ., vol. 59, no. 2, pp. 339-352, Sep. 2012.

[27] W. W. F. Lau, "Learning with Games and Digita 1 Stories in Visual Programming," in Encyclopedia of Information Science and Technology, 2018, pp. 3309-3310.

[28] H. Yildiz Durak, "Digital story design activities used for teaching programming effect on learning of programming concepts, programming self-efficacy, and participation and analysis of student experiences," J. Comput. Assist. Learn., vol. 34, no. 6, pp. 740-752, Dec. 2018.

[29] M. Kordaki and P. Kakavas, "Digital Storytelling As An Effective Framework For The Development of Computational Thinking Skills," in International Conference on Education and New Learning Technologies, 2017,pp. 1-10.

[30]A. Smith et al., "Designing Block-Based Programming Language Features to Support Upper Elementary Students in Creating Interactive Science Narratives," in SIGCSE, 2020, p. 1327.

[31] R. Vinayakumar, K. Soman, and P. Menon, "Digit a 1 Storytelling Using Scratch: Engaging Children Towards Digital Storytelling," in 2018 9th International Conference on Computing, Communication and Networking Technologies, ICCCNT 2018, 2018.

[32]I. Sommerville, Software Engineering, Ninth Edition, Pearson Education, 2011. 